\title{
Citation Analysis of the Texas Tech University's Statistics Faculty: A Study Applied to Collection Development at the University Library
}

\author{
Bill Johnson
}

\begin{abstract}
Texas Tech University is a part of the Texas State University System which opened its doors in 1925. The current enrollment is about 24,000 dispersed among six colleges. The Mathematics Department is one of thirteen in the College of Arts and Sciences with a Ph.D. program. One of those programs is in statistics. Seven faculty members were identified from that program. Their contribution to published research for 1993 and the first half of 1994 was collected and a citation analysis was conducted and subsequently applied to the collection development process at the University Library, where distinct discipline based collection development policies are now being formulated. Two citation patterns were identified: bibliographic and non-bibliographic citations. Bibliographic citations (from the bibliography) numbered 394 from 122 titles. Journals and monographs were the two formats most frequently cited, $46.7 \%$ and $36.9 \%$, respectively. The average age of a citation was 12.3 years. The two most frequently cited journal titles were: Journal of Time Series Analysis and Stochastic Processes and Their Applications. Non-bibliographic citations (not found in the bibliography) were used to identify the more important research topics to this population of faculty: Hermitian operators, Appel polynomials, Laplace transform, Euclidean space, Drichlet polynomials, Lebesgue measure, Hilbert space, and Taylor expansion. Since the conclusion of this study, the most frequently cited journals and monographs have been acquired or recommended for acquisition in conjunction with the Library's collection development policy for Mathematics.
\end{abstract}

\section{INTRODUCTION}

Citation analyses have been applied to a number of library acquisition activities, yet the utility of these studies have often been questioned. Too often, such a study incorporates a "world wide" data set in a relatively broad discipline. This sort of approach may lack relevance to a specific University, its research specialties, and ultimately its library collection. In order to increase the relevance of this citation analysis to the local institution, sample size and subject focus were limited to the published works of a small group of the University's faculty. Relevance to the University was increased since the faculty at that very institution were studied. The literature incorporated in their research constituted the entire sample rather than a small subset of a universal data set wherein many of the titles may never come near their campus. A byproduct of selecting a small group of local faculty is a very narrow subject focus, in this case statistics. Rather than scanning the mathematics literature and ranking those titles, only the titles directly applicable to statistics were considered and they were applicable to the University in question because they were cited by the faculty at the same institution.

The results of this study are similar to other studies of physical science citation patterns, especially 
mathematics. For example, the study by Rousseau [5] found that the average age of citations in the mathematics literature was much greater than those from other physical sciences, such as physics. The average age of the material cited herein was 12.3 years. Most of the material cited was found in journals $(46.7 \%$ ) while monographs were cited $36.9 \%$ of the time. Most of the material cited by the faculty at Texas Tech University could be found in the University Library, $68.4 \%$ of the journals and $60.0 \%$ of the monographs.

Using the citation analysis as an evaluation tool, various journals and books could be considered for acquisition. While other tools may also be used for this purpose, such as InterLibrary Loan statistics, citation analysis is viewed as a superior tool for examining the usefulness of a library collection to its patrons and as an important element of a collection development policy.

\section{LITERATURE REVIEW}

A brief survey of the literature illustrates the breadth and potential application of conducting a citation analysis. A substantial number of research papers, involving some aspect or application of bibliometrics, have been published. The first five articles discussed here analyze the citation patterns of various physical sciences and three additional articles exemplify the usefulness of such studies.

Peters et. al. [1] used the literature of Chemical Engineering to monitor scientific productivity or "research performance". They found bibliometric analysis to be a valuable tool. Their methodology seemed designed to reinforce rather than examine preconceived notions, however. They suggested that a citation analyses was not useful to the same extent in all sub-fields of chemical engineering since some scientists with "high reputations" turned out to be "bibliometrically invisible". Twenty-one "significant" journals of oceanography were examined by Garfield. [2] Here too, a concern was raised over sub-fields within the discipline. For the purpose of this study, oceanography meant chemical and physical oceanography. Marine biology was excluded. Garfield's intent here was to prioritize journal titles worldwide using the citation patterns of titles from this "core" list.

The work by Spies [3] reviewed fourteen "major" journals of exploration geophysics for "effectiveness". This paper presented a basic tenet of citation analysis as follows: the references that an author cites are a roughly valid indicator of influence, hence value, to his work. A measure of cost effectiveness was also incorporated into this study as subscription costs and citation rates were compared between commercial publications and those produced by professional societies.

Uzun et. al. [4] studied the citation rates of 572 Turkish physics publications that appeared in the source journals listed in the Science Citation Index. This analysis was global in scope, as is commonly the case with citation studies. They examined impact factor, immediacy index, citation frequency, and the nationality of the publishing house. The question which these normal parameters and this normal scope raise for librarians is - "How is this relevant to the local collection for which I have a responsibility to build based upon the research and curriculum program ongoing at my institution"?

Finally, Rousseau [5] presented a citation distribution of mathematics journals, wherein he proposes that a four-year impact factor would be more suited to mathematics than the more or less typical two-year impact factor used in Science Citation Index. Once again, the question of relevancy presents itself.

Three additional sources were examined which addressed the practical application of bibliometrics. Bookstein [6] sought to establish a foundational argument in favor of using citation patterns for collection development. Garfield [7] also claimed that the frequency of journal citations could be used in collection development, even so as to select particular titles of local interest in order to address this issue of relevancy. The article by Swigger and Wilkes [8] attempted to broaden the scope of factors 
used in collection development decisions to include professional judgment of librarians, faculty requests, and use studies. In actuality, this appears to be the most realistic method. They concluded that no one method is totally valid but that citation analyses offered the most reliable approach.

\section{METHODS}

It is evident from this brief survey that citation studies have been conducted on a wide variety of disciplines for diverse reasons. The purpose of this section is to present a simple, practical, relevant tool to assist in the collection development process.

The first step was to identify a specific and workable sub-field of a discipline. As the library liaison to the Mathematics Department, I chose statistics, which consisted of seven faculty members. These individuals were chosen based on the list of faculty research interests provided by the Mathematics Department.

The second step was to search for the published works of each faculty member identified in step one within a suitable time frame. The current and previous years were chosen since they would reflect the most relevant research interests of this group of faculty. Additionally, some members of this group had recently requested that the Library subscribe to a new journal title which began publication by Gordon and Breach in 1991, Journal of Nonparametric Statistics. In order to incorporate this title into the present study and evaluate its suitability for addition to the collection, only recently published articles could be considered. Citations to this title would not be expected to appear in print before 1993 due to the time required for an article to be submitted, reviewed, revised, and appear in print: 18 months to two years.

The following sources were searched: Books in Print, INSPEC, WorldCat, Uncover, Math Reviews, Statistical Theory and Methods Abstracts, and Zentralblatt fur Mathematik und Ihre Grenzgbiete. E-Math, via an Internet connection to the American Mathematical Association, was also used to search Math Reviews a second time.

The third step was to collect the articles found in step two, using InterLibrary Loan as necessary and to review the citation patterns. The entire article was needed, not just the list of references at the end of the article since the number of citations throughout the paper must be considered. Other items of interest may be revealed, as in this case, where the pattern of nonbibliographic citations added an unexpected dimension to this study.

The fourth step was to document the results.. Step five involved analyzing the results. Finally, the findings should be applied to collection development decisions such as purchasing previously unowned but heavily cited items.

\section{RESULTS / APPLICATION}

Two citation patterns were identified, bibliographic and nonbibliographic citations. Both groups may be applied to the collection development process. Fourteen print journal articles were found to be published by the sample faculty in 1993 and the first half of 1994. No books and no electronic sources were identified.

The bibliographic citations were arbitrarily divided into two groups, those cited three or more times and those cited fewer than three times. Those cited more than three times constitute $72 \%$ of the citations in $31 \%$ of the titles. This group is, subsequently, of greater interest to collection development considerations. My goal is to provide at least $90 \%$ of the journals and monographs found in this group of 38 titles. The present composition is as follows:

\section{FORMAT DISTRIBUTION OF HEAVILY CITED TITLES}




\begin{tabular}{lcccccc} 
& \# of Titles & TTU Owned & \multicolumn{2}{c}{ TTU Non-owned } \\
Journals & 21 & $(55.3 \%)$ & 17 & $(81 \%)$ & 4 & $(19 \%)$ \\
Monographs & 12 & $(31.6 \%)$ & 19 & $(75 \%)$ & 3 & $(25 \%)$ \\
Series & 4 & $(10.5 \%)$ & & & & \\
Proceedings & 1 & $(2.6 \%)$ & & &
\end{tabular}

Two journals would need to be added to reach my goal. Therefore, during the next round of discussions, given to this topic, I recommended that the following titles be added to the collection:

* Journal of Time Series analysis

* Stochastic Processes and Their Applications

The three monographs found in this top group, not owned by TTU, have been added to the collection, thereby the collection development decision to support this research by acquiring enough titles to bring library holdings up to $90 \%$ of the frequently cited titles was made and acted upon.

Overall, 394 citations were found in 122 titles, having the following composition:

FORMAT DISTRIBUTION OF ALL BIBLIOGRAPHIC CITATIONS

\begin{tabular}{lcccccc} 
& \# of Titles & TTU Owned & \multicolumn{2}{c}{ TTU Non-owned } \\
Journals & 57 & $(46.7 \%)$ & 39 & $(68.4 \%)$ & 18 & $(31.6 \%)$ \\
Monographs & 45 & $(36.9 \%)$ & 27 & $(60 \%)$ & 18 & $(40 \%)$ \\
Series & 9 & $(7.4 \%)$ & & & & \\
Reports & 7 & $(5.7 \%)$ & & & \\
Proceedings & 3 & $(2.5 \%)$ & & & \\
Thesis/Dissert. & 1 & $(0.8 \%)$
\end{tabular}

Additionally, five titles were never cited and eighteen citations referred to either an unclear title or no title at all in the references at the end of the paper.

Obviously, print journals provided the most research support with monographs coming in a close second. The age of this material is also important, especially in light of the request to add a new journal subscription to the library holdings, Journal of Nonparametric Statistics. What support is there for such a request? The requested title began publication in 1991. The average age of the most heavily cited works (cited three or more times) is 11.2 years and over all of the titles, 12.3 years. This title would not be expected to contribute to the research of this faculty group for some time to come, based upon this citation analysis. In fact, this title was not cited once. Not one faculty member published a paper in this journal and not one ILL request has been made from this institution for this title during the past two years. Therefore, there is no objective substantiation for this purchase.

Various subjective factors must also be considered and it is interesting to consider the weight of subjective versus objective criteria in this process. Science and scientists strive for objectivity, yet science is done by scientists who are by their nature, subjective and not objective. The request for this 
title was made on the basis of the editorial board and the appearance of sample and refereed articles, no measurable qualities. In balancing the equation between art and science, in this case, art tipped the scale and the title was ordered.

The nonbibliographic citations provided an unexpected and useful resource for collection development. Each of the papers in this study referred to (cited) various sources but did not list those sources in a bibliography, hence I have labeled them "nonbibliographic citations". These titles may be found in a dictionary or encyclopedia of mathematics where they are described and placed in the context of the research literature of the field. A list of citations to the original work or works is often included in these Reference sources. The "title" as presented here, offers a topic of apparent research interest to this population of faculty. Books, journals, and other materials related to the most heavily cited topics should be considered for inclusion in the collection. Since a specific title must be matched to a particular topic, another "recommendation" for the title, such as a scholarly review, may be appropriate before a collection development decision is made.

The topics cited most frequently in these papers included Hermitian operators, Appel polynomials, Laplace transform, Euclidean space, Drichlet polynomials, Lebesgue measure, Hilbert space, and Taylor expansion. Entering these terms in WorldCat resulted in a variety of hits. I narrowed the list to recent titles, generally 1993 and 1994 to come up with a list of books relevant to the research interests of this group of faculty. Unfortunately, very few book reviews could be found to evaluate these titles. In some cases, we already had the title. Most, we did not own. I have placed orders for several titles, matching the topical interest of the nonbibliographic citations found in this study.

\section{CONCLUSIONS}

In conclusion, this study provided new and foundational data to characterize and measure the research activity of a local group of mathematicians. This data could contribute to a larger project where results could be compared with other disciplines, both closely and distantly related. The nonbibliographic citations added a new dimension to the citation analysis of the physical sciences which has not been previously described. Objective and substantive information was gathered to provide criteria for collection development decisions.

The relationship between research and teaching in the context of serial subscriptions is important though indirect. Never the less, basic research supports teaching as a foundation supports a structure. Faculty may occasionally assign readings from their own published works for undergraduate use, yet the collection development decision to subscribe to a journal is more heavily influenced by its direct role in research rather than teaching.

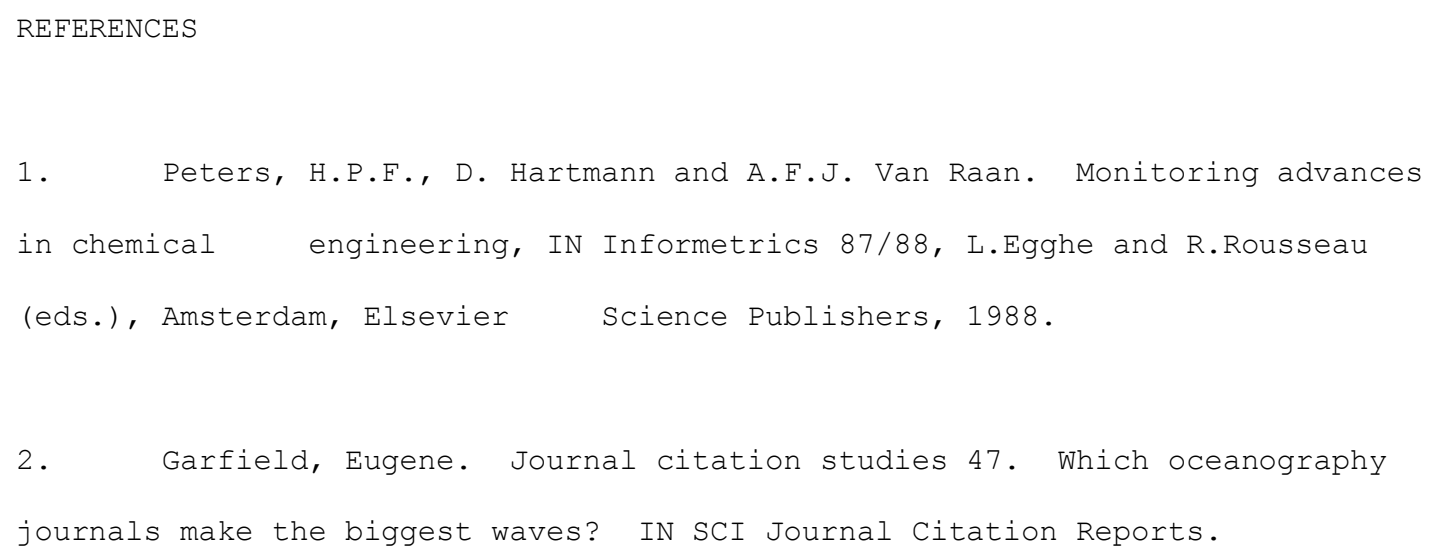


Philadelphia, Institute for Scientific Information Inc. 1988.

3. Spies, Brian R. The effectiveness of journals in exploration geophysics. Geophysics 1991 vol. 56 no. 6 (June) :844-858.

4. Uzun, A., A. Menard, and M.E. Ozel. Citation status of Turkish physics publications in foreign journals:A global analysis. Scientometrics 1993 vol. 28 no. $1: 79-87$.

5. Rousseau, Ronald. Citation distribution of pure mathematics journals. IN Informetrics $87 / 88$. L.Egghe and R.Rousseau (eds.) Amsterdam, Elsevier Science Publishers, 1988.

6. Bookstein, A. Applications of the bibliometric distribution. IN Informetrics 87 / 88. L. Egghe and R. Rousseau (eds.) Amsterdam, Elsevier Science Publishers, 1988.

7. Garfield, Eugene. Citation analysis as a tool in journal evaluation. Science 1972 vol. 178 no. 4060 (3 November):471-479.

8. Swigger, Keith, and Adeline Wilkes. The use of citation data to evaluate serials subscriptions in an academic library. Serials Review 1991 vol. 17 no. 2 (summer) : 41-52.

\section{APPENDIX A}

Faculty and Their Published Works Under Review in the Present Study

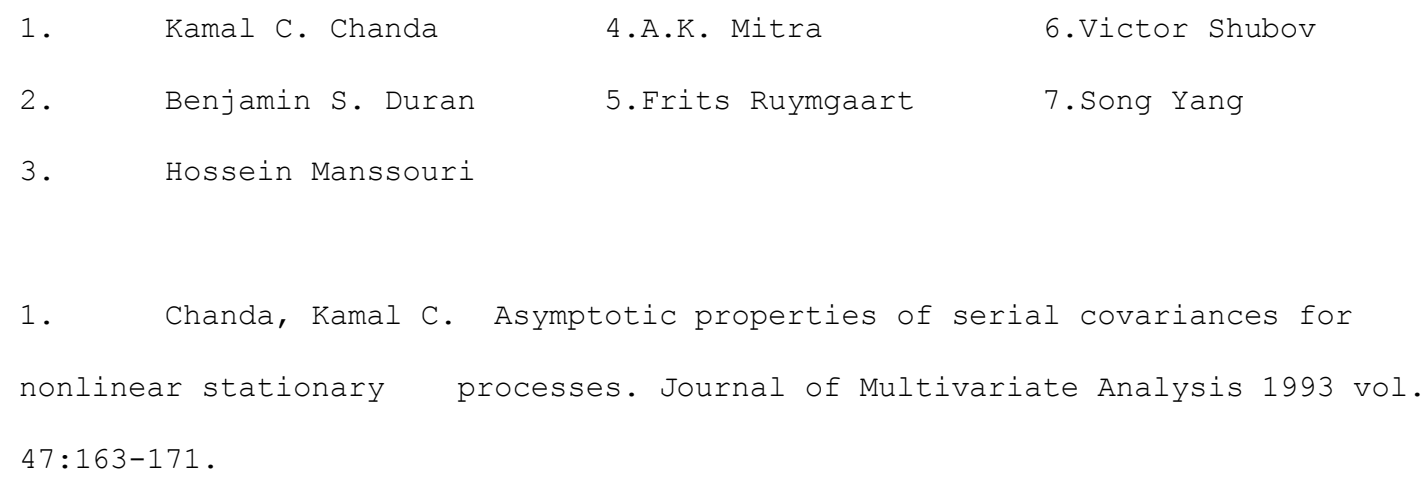


2. Esparza, S.O. and B.S. Duran. Multistate coherent systems and the three modules theorem. Communications in Statistics Part A: Theory and Methods 1993 vol. 22 no. 2:561-573.

3. Martinez-Morales, Manuel and B.S. Duran. A test for randomness based on a complexity measure. Communications in Statistics Part A: Theory and Methods 1993 vol. 22 no. 3:879-895.

4. Mitra, Arun K. A massive parallel computation in Boolean logic. Applied Mathematics and Computation 1993 vol. 57:131-160.

5. Ruymgaart, Frits H. A unified approach to inversion problems in statistics. Mathematical Methods of Statistics 1993 vol. 2 no. 2:130-146.

6. Ruymgaart, Frits H. Conditional empirical, quantile and difference processes for a large class of time series with applications. Journal of Statistical Planning and Inference 1994 vol. 40:15-31.

7. Chauveau, D.E., A.C. van Rooij, and F.H. Ruymgaart. Regularized inversion of noisy laplace transforms. Advances in Applied Mathematics vol.15:186-201.

8. Gilliam David S., Peter Hall and Frits H. Ruymgaart. Rate of convergence of the empirical radon transform. Journal of Multivariate Analysis 1993 vol.44:115-145.

9. Hendriks, H., J.H.M. Janssen and F.H. Ruymgaart. Strong uniform convergence of density estimators on compact Euclidean manifolds. Statistics and Probability Letters 1993 vol. 16:305-311.

10. Puri, Madan L. and Frits H. Ruymgaart. Nonparametric prediction for random fields. Stochastic Processes and Their Applications 1993 vol. 
$48: 139-156$.

11. Puri, Madan L, and Frits H. Ruymgaart. Asymptotic behavior of

L-Statistics for a large class of time series. Annals of the Institute of

Statistical Mathematics. 1993 vol. 45 no. 4:687-701.

12. Martin, Clyde and Victor Shubov. Natural exponential families of probability distributions and exponential-polynomial approximation. Applied Mathematics and Computation 1993 vol. 59:275-297.

13. Martin, Clyde and Victor Shubov. Probability measures, Appel polynomials and polynomial approximation. Applied Mathematics and Computation 1993 vol. 53:277-298.

14. Yang, Song. A central limit theorem for the integrated square error of the kernal density estimators with randomly censored data. Journal of Statistical Planning and Inference 1993 vol. 37:127-143.

Go to Appendix One

Go to Appendix Two

This document may be circulated freely with the following statement included in its entirety:

Copyright Bill Johnson 1996.

This article was originally published in LIBRES: Library and Information Science Electronic Journal_(ISSN 1058-6768) September, 1996 Volume 6 Issue 3.

For any commercial use, or publication (including electronic journals), you must obtain the permission of the author:

\section{Bill Johnson}

To subscribe to LIBRES send e-mail message to listproc@info.curtin.edu.au with the text: subscribe libres [your first name] [your last name] 
Return to Contents Page

Return to Libres Home Page

This page is maintained by Derek Silvester, Dept of Information Studies, Curtin University of Technology, Perth, Western Australia.

Please sent comments and suggestions to Derek@biblio.curtin.edu.au

CRICOS provider code: 00301J 
LIBRES: Library and Information Science Research

Electronic Journal ISSN 1058-6768

1996 Volume 6 Issue 3; September

Quarterly LIBRE6N3 APPENDX1

\section{Appendix One}

of

Citation Analysis of the Texas Tech University's Statistics Faculty: A Study Applied to Collection Development at the University Library

Citation Analysis Fall 1994

Department of Mathematics: Statistics Group

Title

\# of Times

Av. Age Format

TTU

Cited

Years

Owned

Annals of statistics

Annals of probability

Journal of the Society for Industrial and Applied Mathematics

Applied mathematics and computation

Journal of multivariate analysis 
IEEE transactions on information theory
10
17.5
y

Journal of time series analysis
8
3.8
n

Acta applicandae mathematicae

$8 \quad 2.6 \quad j \quad$ y

Proceedings of the Steklov Institute of Mathematics
7
5.0
proceedings
Y

Information and control

26.8

Journal of applied probability

$\begin{array}{llll}6.3 & \text { j } & y\end{array}$

Advances in electronics and electron physics

$5 \quad 4.0 \quad$ j $\quad y$

Emperical processes with applications in statistics

$\begin{array}{llll}7.6 & \mathrm{~m} & \mathrm{y}\end{array}$

Stochastic processes and their applications

$\begin{array}{llll}7.2 & \text { j } & \mathrm{n}\end{array}$

International statistical review

$\begin{array}{llll}5.8 & j & \text { j }\end{array}$

Annals of mathematical statistics

$\begin{array}{llll}23.6 & j & \text { j }\end{array}$

The radon transform

$5 \quad 13.0 \quad$ m $\quad y$

Nonparametric functional estimation
5
10.0
m

Journal of the American Statistical Association

Spectral analysis and time series vol.1 
Finite difference equations and simulations

Theory of probability

Censoring and stochastic integrals

Elektronische informationsverdbeitung und kybernetik

Statistica sinica

Mathematical biosciences

Stationary sequences and random fields

3

Encyclopedia of statistical sciences

(5)

3

Encyclopedia of statistical sciences

8.0

series

3

7.0

series

Linear Integral equations

$$
3
$$

4.0

m

Theory of Bessel functions

$$
3
$$

35.0

m

Computers and mathematics with applications

3.0

Polynomial expansions of analytic functions

$$
3
$$

29.0

m

Selected translations in mathematical statistics and probability 
Physik der selbstorganisation und evolution

3

11.0

m

$\mathrm{n}$

Advances in applied probability

11.0

j

Y

38 Titles (31.0\%)

285 citations 11.3 av yrs

$(72.0 \%)$

\# of Titles

Journals

$21(55.3 \%)$

Monographs

$12(31.6 \%)$

Series

$4 \quad(10.5 \%)$

Proceedings

$1 \quad(2.6 \%)$
TTU Owned

$17(81.0 \%)$

$9(75.0 \%)$

$3(25.0 \%)$

Average age for journals in this set - 10.3 years, and monographs - 16.1 years. Methods of modern mathematical physics I functional analysis

21.0

m

Y

Journal of complexity

2

2.0

j

n

Proceedings of the royal society of London series A mathematical and physical sciences

2

11.0

j

Y

Asymptotic optimality for inverse estimation problems 
Advances in applied mathematics

$$
2
$$

1.0

j

Stochastic models in reliability theory$$
2
$$

9.0

m

n

Journal of probability

$$
2
$$

9.0

j

n

Algorithmic information theory

$$
2
$$

6.0

m

n

Journal of the Royal Statistical Society (b) Methodological

2

6.0

j

Y

Bulletin of the American Mathematical Society

$$
2
$$

53.0

j

y

Matematica aplicadae computacional

$$
2
$$

5.5

j

$\mathrm{n}$

Probability theory and related fields

2

5.0

j

Y

Stochastic complexity in statistical inquiry

$$
2
$$

4.0

m

n

Special functions

$$
2
$$

33.0

m

y

Mathematical theory of probability and statistics

2

29.0

m

Y

Communications on pure and applied mathematics$$
2
$$

Russian mathematical surveys

$$
2
$$

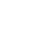

Journal of computer system sciences

2

20.0

j
Y Y

Conditional empirical, quantile, and difference processes for a large class of time series with applications 
Interpolation and approximation

Theory of probability and its applications

$2 \quad 16.5 \quad$ j $\quad$ y

International journal of general systems

Zeitwende monatsschrift

Methods of numerical integration
2
10.0
m

Automatica

$2 \quad 15.0 \quad$ j $\quad$ y

Lecture notes in statistics
1
9.0
series

Probability theory with applications
1
9.0
m

Zeitschrift fuer wahrescheinlichkeitstheorie und verwandte gebiete

$19.0 \quad$ j $\quad y$

Contemporary mathematics

$1 \quad 7.0 \quad$ j $\quad y$

Statistical science

$17.0 \quad$ j $n$

Statistical estimation and optimal recovery
1
4.0
report

Gaussia deconvolution via differentiation
1
3.0
report

Maximum entropy and the nearly black object

$13.0 \quad$ report $n$

Proceedings of the NATO-ASI conference on nonparametric functional 
LIBRES: Library and Information Science Research

Electronic Journal ISSN 1058-6768

1996 Volume 6 Issue 3; September

Quarterly LIBRE6N3 APPENDX2

\section{Appendix Two}

of

Citation Analysis of the Texas Tech University's Statistics Faculty: A Study Applied to Collection Development at the University Library

Nonbibliographic Citations

Title

\# of Times Cited

Hermitian operator

Appel polynomials

Laplace transform

Euclidean space

Drichlet polynomials

Lebesgue measure

Hilbert space

Taylor expansion

Bennett's inequality

Volterra expansion 
$\begin{array}{ll}\text { Stiefel manifolds } & 7\end{array}$

$\begin{array}{ll}\text { Three Modules Theorem } & 7\end{array}$

$\begin{array}{ll}\text { Binary Coherent Systems } & 6\end{array}$

Boolean algebra $\quad 6$

Borel-Cantelli lemma $\quad 6$

$\begin{array}{lr}\text { Borel set } & 6\end{array}$

Holder continuity $\quad 6$

$\begin{array}{lr}\text { Fourier transform } & 5\end{array}$

$\begin{array}{lr}\text { Turine machines } & 5\end{array}$

Kolmos-Major-Tusnudy approximation 4

$\begin{array}{lr}\text { Sobolev space } & 4\end{array}$

$\begin{array}{ll}\text { ARMA } & 3\end{array}$

Bahadur-kiefer representation 3

Brownian bridge 3

Cauchy distribution 3

Grassman manifolds $\quad 3$

Markov sequence $\quad 3$

$\begin{array}{lr}\text { Abel operator } & 2\end{array}$

Banach space $r$

$\begin{array}{ll}\text { Cartesian product } & 2\end{array}$

Cramer's rule 2

$\begin{array}{lr}\text { Euler polynomial } & 2\end{array}$

Fourier-Plancherel transform 2

$\begin{array}{ll}\text { Keplan-Meier process } & 2\end{array}$

Kriging's problem 2

$\begin{array}{lr}\text { Leibnitz's rule } & 2\end{array}$

Multistate Coherent Systems $r$ 
$\begin{array}{ll}\text { Poisson variables } & 2\end{array}$

$\begin{array}{lr}\text { Radon-Nikodym theory } & 2\end{array}$

$\begin{array}{lr}\text { Richard von Mises } & 2\end{array}$

Singular Value Decomposition SVD 2

Vandermond type determinant 2

$\begin{array}{lr}\text { Vapnik-Cervonenkis number } & 2\end{array}$

$\begin{array}{ll}\text { Zernike polynomials } & 2\end{array}$

Abel-Gontschoroff conditions 1

Bessel function $r$

Bohman's inequality $r$

Cauchy-Schwartz inequality 1

Chebyshers inequality 1

Chernoff-Savage L-Statistic $r$

Complexity of Description Measure 1

$\begin{array}{lr}\text { Cramer-VonMises statistic } & 1\end{array}$

Dirac function $\quad 1$

$\begin{array}{lr}\text { Euler-MacLaurin formula } & 1\end{array}$

Hopital's rule $r$

Integral Mean Squarred Error IMSE 1

Klein-Gordon equation $r$

Kolmogorov complexity $r$

Kromecker symbol $r$

Kronecker delta $r$

Modular Factorization of a System 1

$\begin{array}{lr}\text { Non-Bayesian approach } & 1\end{array}$

Riemannian volume $r$

Rozenblatt-Parzen estimator $r$

$\begin{array}{lr}\text { Schwartz distribution } & 1\end{array}$ 
Stone's formula

Tikhonov's regularization scheme 1

Wicksell's particle size estimation problem 1

Go to Main Article

Go to Appendix One

This document may be circulated freely

with the following statement included in its entirety:

Copyright? Johnson 1996.

This article was originally published in

LIBRES: Library and Information Science

Electronic Journal_(ISSN 1058-6768) September, 1996

Volume 6 Issue 3.

For any commercial use, or publication

(including electronic journals), you must obtain

the permission of the author:

\section{Bill Johnson}

To subscribe to LIBRES send e-mail message to listproc@info.curtin.edu.au

with the text:

subscribe libres [your first name] [your last name]

Return to Contents Page

Return to Libres Home Page

This page is maintained by Derek Silvester, Dept of Information Studies, Curtin University of Technology, Perth, Western Australia.

Please sent comments and suggestions to Derek@biblio.curtin.edu.au 